\title{
Article \\ The Impact of Different Internet Application Contexts on Knowledge Transfer between Enterprises
}

\author{
Xingong Li and Xiaokai $\mathrm{Li}$ * (D) \\ School of Business, Henan University, Kaifeng 475000, China; lxg@henu.edu.cn \\ * Correspondence: kf95549@163.com
}

check for updates

Citation: Li, X.; Li, X. The Impact of Different Internet Application Contexts on Knowledge Transfer between Enterprises. Systems 2021, 9, 87. https://doi.org/10.3390/ systems 9040087

Academic Editor: Alberto Paucar-Caceres

Received: 23 November 2021 Accepted: 9 December 2021 Published: 14 December 2021

Publisher's Note: MDPI stays neutral with regard to jurisdictional claims in published maps and institutional affiliations.

Copyright: (c) 2021 by the authors. Licensee MDPI, Basel, Switzerland. This article is an open access article distributed under the terms and conditions of the Creative Commons Attribution (CC BY) license (https:// creativecommons.org/licenses/by/ $4.0 /)$.

\begin{abstract}
This paper investigates the effect of different Internet application scenarios on the forward and reverse knowledge transfer between architecture enterprises and component enterprises in the context of modular production in manufacturing enterprises. After dividing the Internet contexts into three the perspectives of Internet tools, Internet platforms, and Internet resources, this paper adopts a system dynamics approach to construct a causality model and a system flow diagram of the influence of different Internet contexts on the knowledge transfer between architecture enterprises and component enterprises, and uses Vensim PLE software to simulate and conduct a sensitivity analysis of the model. The results show that the three Internet contexts, namely Internet tools, Internet platforms, and Internet resources, can promote both positive and negative knowledge transfer between architecture enterprises and component enterprises, and exhibit a steadily growing trend of promotion; Internet tools and Internet resources are more conducive to positive knowledge transfer from architecture enterprises to component enterprises, and Internet platforms have a stronger facilitation effect on the reverse knowledge transfer from the component enterprises to the architecture enterprises. Our research offers useful recommendations for businesses on how to utilize various Internet settings to promote and assist effective knowledge transfer.
\end{abstract}

Keywords: systems dynamics; internet application scenarios; knowledge transfer; architecture enterprises; component enterprises

\section{Introduction}

The process of technology transfer is accompanied by knowledge flows [1]. Globalization has decentralized the production of components linked through global value chains (GVCs) specifically in the emerging market countries such as China, where GVCs are embedded in the form of subcontractors or original equipment manufacturers (OEMs) who are gradually acquiring, upgrading technologies, and accumulating a wealth of production knowledge [2]. An enterprise's ability to innovate is the result of its knowledge accumulation, which is not only internal but also depends to a greater extent on the absorption of external knowledge [3]. The uptake of external knowledge by enterprises, through internalization, externalization, and socialization, provides the basis and potential for technological innovation [4]. Effective corporate knowledge management practices are often based on good knowledge sharing activities [5], as enterprises are increasingly turning to their external partners to access knowledge resources for innovation success [6]. Knowledge transfer is more conducive to an enterprise's ability to innovate than knowledge itself.

The use of the Internet has enhanced the ability to disseminate and share knowledge [7] by allowing architecture enterprises and component enterprises to stay linked and instantly interact, resulting in a shift in the inter-enterprise knowledge transfer environment. First, the use of the Internet not only facilitates the transfer of existing explicit knowledge [8] but also accelerates the conversion of tacit knowledge to explicit knowledge by enhancing direct human interaction [9] by increasing the ease of communication across boundaries for the organizational members and by further facilitating the flow of tacit knowledge. 
Second, the Internet has improved the way that organizations generate and disseminate information, breaking through the temporal and spatial limitations of information transfer, and quickly achieving knowledge and information penetration [10], thereby enhancing the effectiveness of inter-enterprise knowledge transfer. Third, the application of the Internet makes knowledge less sticky and promotes inter-enterprise knowledge transfer. However, the extent of Internet adoption varies greatly across regions and industries [11] by manifesting itself in different Internet adoption contexts. The inevitable differential impact of different Internet adoption contexts on knowledge transfer is an important but neglected contextual factor that requires further attention. In summary, Internet application significantly facilitates knowledge transfer between architecture enterprises and component enterprises; however, existing studies ignore the fact that the degree of enterprise Internet application is differentiated, i.e., different Internet application contexts will inevitably have a differentiated impact on inter-enterprise knowledge transfer.

Since the 1990s, manufacturing production has entered a period of great modularity as more and more products are connected by modules, and the interdependence between component and architecture enterprises has gradually increased in a collaborative innovation process using modules as a vehicle. Based on the link between knowledge classification and production task characteristics [12-15], architectural knowledge defines the way in which components are connected while maintaining the core design concept that component knowledge is associated with a set of physical components defined through an architectural design. The knowledge related to the physical components that are connected through a set of interfaces is defined by the architectural design. Typically, architecture enterprises focus on the integration tasks and develop primary architecture knowledge in general, while component enterprises focus on component tasks and knowledge [13]. With the development of production at scale, component enterprises are no longer limited to producing component products according to the technical standards defined by the architecture enterprise but have become active participants in the development of complex and sophisticated products [16]. Architecture enterprises lacking component-specific knowledge from component enterprises have also lost their competitive advantage in the process of new product development [14]. The knowledge boundary of the enterprise also does not coincide with the production boundary $[17,18]$, as the product does not fully reflect the knowledge of the enterprise, and the knowledge required for a particular product cannot be obtained entirely from within the enterprise that produces it [14]. Often, the architecture enterprise will initiate knowledge transfer to the component enterprise so that the modules 'contracted' by the component enterprise conform to the 'interface rules' and thus ensure the quality of the product integration. The architecture enterprise is generally concerned with knowledge at the architectural level; however, when faced with the new technologies or more complex production situations, it is beneficial if the architecture enterprise has more component-specific knowledge to enhance the production system integration capabilities $[13,17]$. Thus, effective knowledge transfer between architecture and component enterprises can help organizations acquire continuous innovation capabilities.

Most of the existing studies related to the inter-enterprise knowledge transfer have been discussed from a static perspective. However, inter-enterprise knowledge transfer is a circular, dynamic, and complex feedback system which conforms to the boundary settings and conditions of the system dynamics modeling [19]. Therefore, this paper uses a system dynamics approach to explore the differential effect of different Internet application scenarios on the knowledge transfer process between architecture and component enterprises in the context of modular production in manufacturing enterprises. This study can help enterprises gain insights into the intrinsic laws of the Internet context which affects knowledge transfer and provides valuable insights for improving the efficiency of knowledge transfer between architecture and component enterprises.

The remainder of the paper is organized as follows. Section 2 reviews and discusses related research work, Section 3 constructs the system dynamics model for this study, 
Section 4 presents the model testing and sensitivity analysis, and, finally, the conclusions and implications of the paper are outlined in Section 5.

\section{Literature Review and Conceptual Models}

\subsection{Knowledge Transfer between Architecture and Component Enterprises in Modular Production}

In modular production, components are physical parts with well-defined functions that embody the core design of a product $[15,20]$ and architectures are standardized rules of association and interfaces between components [21,22], thus combining the mutually independent components into complex system products [23]. Component enterprises 'contract' the processing, production, and design of a component of the architecture enterprise, thus gaining a 'learning opportunity'; component enterprises are independent in ensuring the compatibility of the 'contracted' modules, i.e., following common interface standards. The architecture enterprise knows the entire module architecture including product structure, module interfaces, and testing standards [15], which allows for the effective control of the modular production process and results in the component enterprise. The product structure also defines which modules are the building blocks of the system and how they function while the module interface defines the arrangement and connection between modules. Furthermore, test criteria are used to verify that the modules comply with the product design rules, meet the module interface criteria, and to test the performance of the modules [22]. Initially, component enterprises often only have knowledge of the components associated with their 'contracted' module; however, they gradually accumulate significant production knowledge during component production and begin to expand their organizational boundaries to become active participants in the development of more complex and sophisticated products [16,24].

Architecture enterprises focus on product integration and accumulate a wealth of architecture knowledge, while the component enterprises focus on the component production and accumulate a large amount of component knowledge $[13,14]$. Knowledge in modular production, as an innovation input, has externalities and significant positive spillovers with regards to other associated enterprises. As production tasks are 'outsourced', the architecture enterprise transfers component-related knowledge to the component enterprise, thus ensuring the quality of the integrated product. However, when architecture enterprises are in a business environment where complex new technology products are being developed, component-specific knowledge is critical [13,14]. Drawing on Crespo et al. [25], this paper classifies knowledge transfer between architecture enterprises and component enterprises into two types based on the direction of knowledge transfer: forward knowledge transfer from the architecture enterprises to the component enterprises, and reverse knowledge transfer from the component enterprises to the architecture enterprises. Both forward and reverse knowledge transfers may include selective knowledge disclosure with the subjective will, such as active knowledge transfer in the form of paid transfer of patents, and passive knowledge transfer in the form of passive and uncontrollable knowledge leakage. As there is 'back-to-back competition' [22] in modular production, i.e., each component enterprise processes, produces, designs, and develops modules independently, there is no knowledge transfer between component enterprises, and knowledge transfer generally exists only between architecture enterprises and component enterprises.

\subsection{The Effect of Different Internet Scenarios on Knowledge Transfer between Architectural and Component Enterprises}

Knowledge transfer is processual in that it occurs within a certain temporal and spatial context, i.e., knowledge transfer is embedded in a context [26,27]. The context of knowledge transfer influences, indirectly, the subject and object of knowledge transfer through external forces and has an important impact on the quality and efficiency of knowledge transfer. The widespread use of the Internet has facilitated inter-enterprise knowledge transfer, accelerated the frequency of contact between architecture enterprises and component enterprises in modular production, and has increased the speed of potential change owing 
to accumulated knowledge. According to the characteristics and value evolution laws in the operation of the economic system after the birth of the Internet, and drawing on the research results of Yang et al. [28], the Internet context is divided into three contexts: Internet tools, Internet platforms, and Internet resources, and although these three types of Internet contexts are created and developed in chronological order, their evolutionary processes are not "one after the other". Internet tools mainly include the emergence and use of tools such as electronic data interchange technology, email, browsers, and search engines, which enable inter-enterprise knowledge transfer to break through time and space restrictions, enhance the efficiency of knowledge and information retrieval, transmission, and storage, and improve transfer performance, thereby reflecting the instrumental characteristics of the Internet. Internet platforms mainly refer to online economic models based on Internet platforms, such as e-commerce enterprises such as Amazon, eBay, China Taobao, and Jingdong, financial platforms that carry out payment and settlement, such as P2P lending, online finance, and financial credit, and instant interactive platforms, represented by Ticktock and WeChat, which can make the interaction between architecture enterprises and component enterprises more direct and flattened, and knowledge information services and transaction activities more flexible and convenient. Internet resources mainly refer to cloud computing and big data, which are derivatives of the Internet and are an important category of strategic man-made resources. Yan [29] also points out that digital technology based on the Internet makes data an economic resource with different characteristics from natural resources. Internet big data resources have advantageous features such as large information capacity, diversity of value, fast generation, no diminishing marginal value in transmission, and the more it is consumed, the more the total amount increases instead of decreasing, which is conducive to the improvement of the efficiency of knowledge transfer between enterprises.

Knowledge characteristics are a key factor in the transfer of knowledge [30,31]. Knowledge can be divided into explicit and tacit knowledge based on its nature [32,33]; explicit knowledge is easy to encode and is mainly expressed and transferred through the use of words, numbers, etc. [34,35]; tacit knowledge is difficult or even uncodifiable and is deeply embedded in organizational systems [36,37], such as beliefs and emotions [38], personal expertise, insights, and intuition [34]. On the other hand, tacit knowledge is more effectively transferred through face-to-face interactions $[9,39]$. The use of the Internet has reduced the cost of inter-enterprise knowledge transfer and has facilitated knowledge uptake [9]. Deploying the Internet of Things (IoT) on the Internet infrastructure enhances the interaction between people and things [40] and facilitates the transfer of tacit knowledge between enterprises. By constructing a media mapping framework, Chennamaneni and Teng [41] found that Internet platforms are more conducive to the transfer of tacit knowledge between enterprises, and Email and other Internet tools, on the other hand, are more conducive to explicit knowledge dissemination.

Enterprises are the main agents of knowledge transfer. The Internet has fundamentally changed the way that enterprises acquire and transfer knowledge [41]. The application of Internet tools has enhanced the ability of enterprises to collect information, process data, and apply digital technologies to aid in decision-making [42]; enterprises can use Internet platforms not only to explore new models for business growth [43], but also to take advantage of the learning opportunities created for the enterprises by the Internet platforms [44], to access online communities such as business incubators and accelerators [45], and to establish instant connections with professionals [46], thereby increasing the efficiency of inter-enterprise knowledge transfer.

The data revolution has brought opportunities and challenges to all industries. Today, all businesses rely heavily on data to improve overall operational efficiency to gain a strategic advantage [47]. Enterprises have been searching for data about operations, supply chains, customer transactions, etc., and then analyzing the data to gain valuable information to secure their competitive advantage. With the further development of Internet technology, the cost of data search, storage, and processing has dramatically decreased, while emerging 
Internet tools such as cloud computing, Internet of Things, and social networks have contributed to the fact that the variety and scale of data in human society is growing at an unprecedented rate, and enterprises are moving from simply identifying important data and making it available to managers and decision makers [48,49], to gradually beginning to use data as a fundamental knowledge resource. For example, tacit knowledge can be extracted from corporate search engines and social media click records [50], and an in-depth analysis of the corporate operational and transactional data [48] can facilitate the generation of innovative ideas.

\subsection{Conceptual Model}

The modular production network is a topological structure, connected by the interface rules and guaranteed by the allocation rules [51], based on which the architecture enterprise is the core enterprise and the component enterprise is the non-core enterprise in the modular production network organization, and both form a new type of cooperative relationship. Knowledge as an important resource for enterprises is related to their past activities [52], which makes inter-enterprise knowledge transfer path-dependent. The knowledge potential difference generated by the core enterprise (architecture enterprise) having a high initial knowledge stock drives forward knowledge transfer to the non-core enterprise (component enterprise) [53], while heterogeneous knowledge needs (e.g., component-specific expertise) drive reverse knowledge transfer from the component enterprise to the architecture enterprise, both of which are affected by the different Internet scenarios during the knowledge transfer process. To maintain their core position in the modular production network, architecture enterprises have a high independent knowledge innovation rate and the intention to maintain the dominant position, while component enterprises have a relatively low independent knowledge innovation rate and the intention to raise their status. Architecture enterprises, component enterprises, and the synergistic innovation system in which they operate all face the problem of knowledge aging.

Based on the analysis in Sections 2.1-2.3, and drawing on the research results of Zhang et al. [54], Chen et al. [55], and Wang [56], this paper constructs a conceptual model of the impact of different Internet application contexts on knowledge transfer between architecture enterprises and component enterprises, as shown in Figure 1.

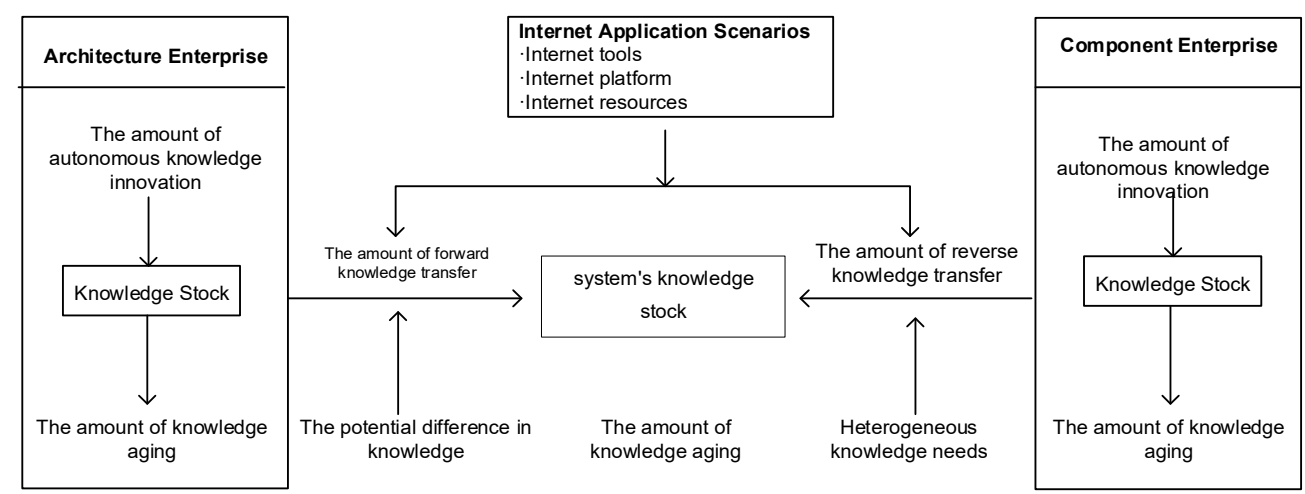

Figure 1. Conceptual model.

\section{Establishment of a System Dynamics Model}

\subsection{Model Suitability Analysis}

Central to knowledge transfer is the continuous flow of knowledge between enterprises that can be accumulated, reused, and recombined to create new knowledge to generate its potential benefits [37]. Knowledge transfer between structuring and component enterprises is a flow of information with an interactive relationship, and the stock and transfer of knowledge exhibit a continuous increase in aging, which is consistent with the basic research conditions of the system dynamics [57]. Paucar-Caceres \& Pagano [58] argue 
that systems thinking and knowledge management have the same conceptual basis and advocate for a systematic approach to knowledge management research.

System dynamics (SD) is an effective method for analyzing non-linear complex systems based on system feedback control theory and using computer simulation techniques to integrate internal and external feedback information of the system [19,54]. An increasing number of scholars use SD as a method to study inter-enterprise knowledge transfer. For example, Zhang et al. [54] used SD to study the impact of resource heterogeneity on knowledge transfer in R\&D alliances. Wang [56] used SD to explore knowledge transfer in the context of organizational crisis management. There are many factors influencing knowledge transfer between architecture enterprises and component enterprises in the modular production of the manufacturing industry in the Internet context, and the relationship between the factors is complex. Using the system dynamics method can parallelize the influencing factors and can also abstract the interrelationship between the influencing factors; the innovation system composed of architecture enterprises and component enterprises has relatively clear system boundaries: the existence of positive and negative within the system. The knowledge transfer within the system has certain predictability and regularity, rather than being random and unstable. Therefore, this paper constructs a system dynamics model and uses causality diagrams, system flow diagrams, and simulation analysis to comprehensively analyze the influence mechanism of knowledge transfer between architecture enterprises and component enterprises in a manufacturing modular production under different Internet contexts.

\subsection{The Causality Model and Main Feedback Loops}

In the production of modular products, architecture enterprises are at the core and have a strong desire to maintain their dominant position, while component enterprises are at a lower system position but have a strong desire to climb up the hierarchy. Due to the difference in knowledge stock and independent innovation capability, there is a certain knowledge potential difference between architecture and component enterprises, which leads to positive knowledge transfer between enterprises. Component enterprises search for and select external knowledge that can match the market niche, and after digestion and absorption, generate a large amount of heterogeneous and complementary knowledge, which is less than that of architecture enterprises in terms of total knowledge; however, it dominates in a single knowledge system and forms a local potential difference; the demand of architecture enterprises for heterogeneous and complementary knowledge of component enterprises leads to reverse knowledge transfer from low-potential component enterprises to high-potential architecture enterprises. Positive knowledge transfer is influenced by the knowledge sharing rate of architecture enterprises, knowledge potential difference, knowledge threshold, and the Internet context. The amount of reverse knowledge transfer is influenced by the Internet context, the knowledge sharing rate of the component enterprises, and the knowledge stock of the component enterprises. The knowledge retention rate of architecture enterprises portrays the knowledge retention of architecture enterprises after excluding active knowledge transfer and passive knowledge transfer; knowledge potential difference is the gap between the knowledge stock of architecture enterprises and component enterprises; knowledge threshold is a prerequisite for knowledge transfer, under which architecture enterprises will make positive knowledge transfer to the component enterprises; the Internet context mainly consists of Internet tools, Internet platforms, and Internet resources. The knowledge stock of innovation systems is influenced by the amount of positive knowledge transfer, the amount of reverse knowledge transfer, and the amount of knowledge aging.

Accordingly, this paper constructs a causal model of knowledge transfer between architecture enterprises and component enterprises in modular production in the Internet scenario, as shown in Figure 2. 


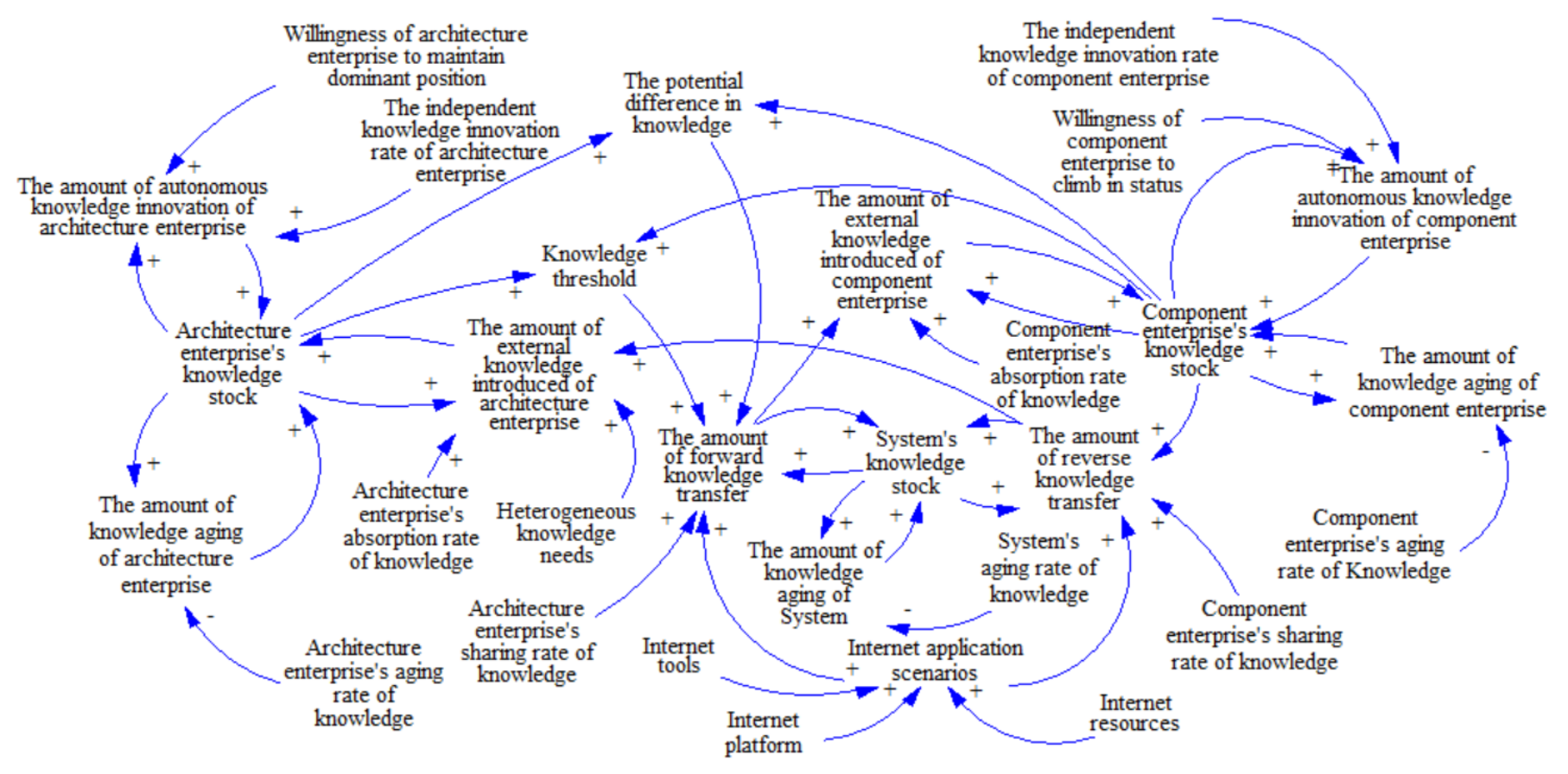

Figure 2. Causality.

Based on the feedback of the system as expressed by the loops in the causality model in Figure 2, a model can be obtained which includes 14 main feedback loops, as shown in Table 1.

Table 1. Feedback loops.

\section{Main Loops}

Feedback loops1

Feedback loops2

Feedback loops3

Feedback loops4

Feedback loops5

Feedback loops6

Feedback loops7

Feedback loops8

Feedback loops9

Feedback loops10

Feedback loops11

\section{Description}

Architecture enterprise's knowledge stock $\rightarrow$ The amount of autonomous knowledge innovation of architecture enterprise $\rightarrow$ Architecture enterprise's knowledge stock

Architecture enterprise's knowledge stock $\rightarrow$ The amount of external knowledge introduced of architecture enterprise $\rightarrow$ Architecture enterprise's knowledge stock

Architecture enterprise's knowledge stock $\rightarrow$ The amount of knowledge aging of architecture enterprise $\rightarrow$ Architecture enterprise's knowledge stock

Component enterprise's knowledge stock $\rightarrow$ The amount of autonomous knowledge innovation of component enterprise $\rightarrow$ Component enterprise's knowledge stock

Component enterprise's knowledge stock $\rightarrow$ The amount of external knowledge introduced of component enterprise $\rightarrow$ Architecture enterprise's knowledge stock

Component enterprise's knowledge stock $\rightarrow$ The amount of knowledge aging of component enterprise $\rightarrow$ Architecture enterprise's knowledge stock System's knowledge stock $\rightarrow$ The amount of forward knowledge transfer $\rightarrow$ System's knowledge stock System's knowledge stock $\rightarrow$ The amount of reverse knowledge transfer $\rightarrow$ System's knowledge stock System's knowledge stock $\rightarrow$ The amount of knowledge aging of system $\rightarrow$ System's knowledge stock

Architecture enterprise's knowledge stock $\rightarrow$ Knowledge threshold $\rightarrow$ The amount of forward knowledge transfer $\rightarrow$ System's knowledge stock $\rightarrow$ The amount of reverse knowledge transfer $\rightarrow$ The amount of external knowledge introduced of architecture enterprise $\rightarrow$ Architecture enterprise's knowledge stock

Architecture enterprise's knowledge stock $\rightarrow$ The potential difference in knowledge $\rightarrow$ The amount of forward knowledge transfer $\rightarrow$ System's knowledge stock $\rightarrow$ The amount of reverse knowledge transfer $\rightarrow$ The amount of external knowledge introduced of architecture enterprise $\rightarrow$ Architecture enterprise's knowledge stock 
Table 1. Cont.

\begin{tabular}{cl}
\hline Main Loops & \multicolumn{1}{c}{ Description } \\
\hline Feedback loops12 & $\begin{array}{l}\text { Component enterprise's knowledge stock } \rightarrow \text { The amount of reverse knowledge transfer } \rightarrow \text { System's } \\
\text { knowledge stock } \rightarrow \text { The amount of forward knowledge transfer } \rightarrow \text { The amount of external knowledge } \\
\text { introduced of component enterprise } \rightarrow \text { Component enterprise's knowledge stock }\end{array}$ \\
\hline
\end{tabular}

Component enterprise's knowledge stock $\rightarrow$ the potential difference in knowledge $\rightarrow$ The amount of

Feedback loops13 forward knowledge transfer $\rightarrow$ The amount of external knowledge introduced of component enterprise $\rightarrow$ Architecture enterprise's knowledge stock

Feedback loops14

Component enterprise's knowledge stock $\rightarrow$ knowledge threshold $\rightarrow$ The amount of forward knowledge transfer $\rightarrow$ The amount of external knowledge introduced of component enterprise $\rightarrow$ Architecture enterprise's knowledge stock

\subsection{Model Assumptions and System Flow Chart}

To clarify the prerequisites and conditions for the operation of the knowledge transfer system between architecture enterprises and component enterprises, the following basic assumptions are put forward in this paper: (1) the initial knowledge stock of architecture enterprises is higher than that of the component enterprises, and there is a knowledge potential difference between the two. As long as the knowledge threshold condition is satisfied, the knowledge potential difference will prompt the architecture enterprises to transfer the positive knowledge to the component enterprises. (2) The motivation for the autonomous innovation of the architecture enterprises is the willingness to maintain the dominant position in the innovation system, while the motivation for the autonomous innovation of the component enterprises is the willingness to climb upwards in terms of position in the innovation system. (3) The heterogeneous and complementary knowledge generated by component enterprises creates a local potential difference, which drives reverse knowledge transfer between enterprises.

According to the model assumptions and causal relationships, it is necessary to classify the variables involved in the model, establish the mathematical relationships between the variables, and build the corresponding system flow diagram (see Figure 3 for details). Therefore, we have included 3 state variables, 9 flow rate variables, 6 auxiliary variables, and 12 constants (see Table 2 for details).

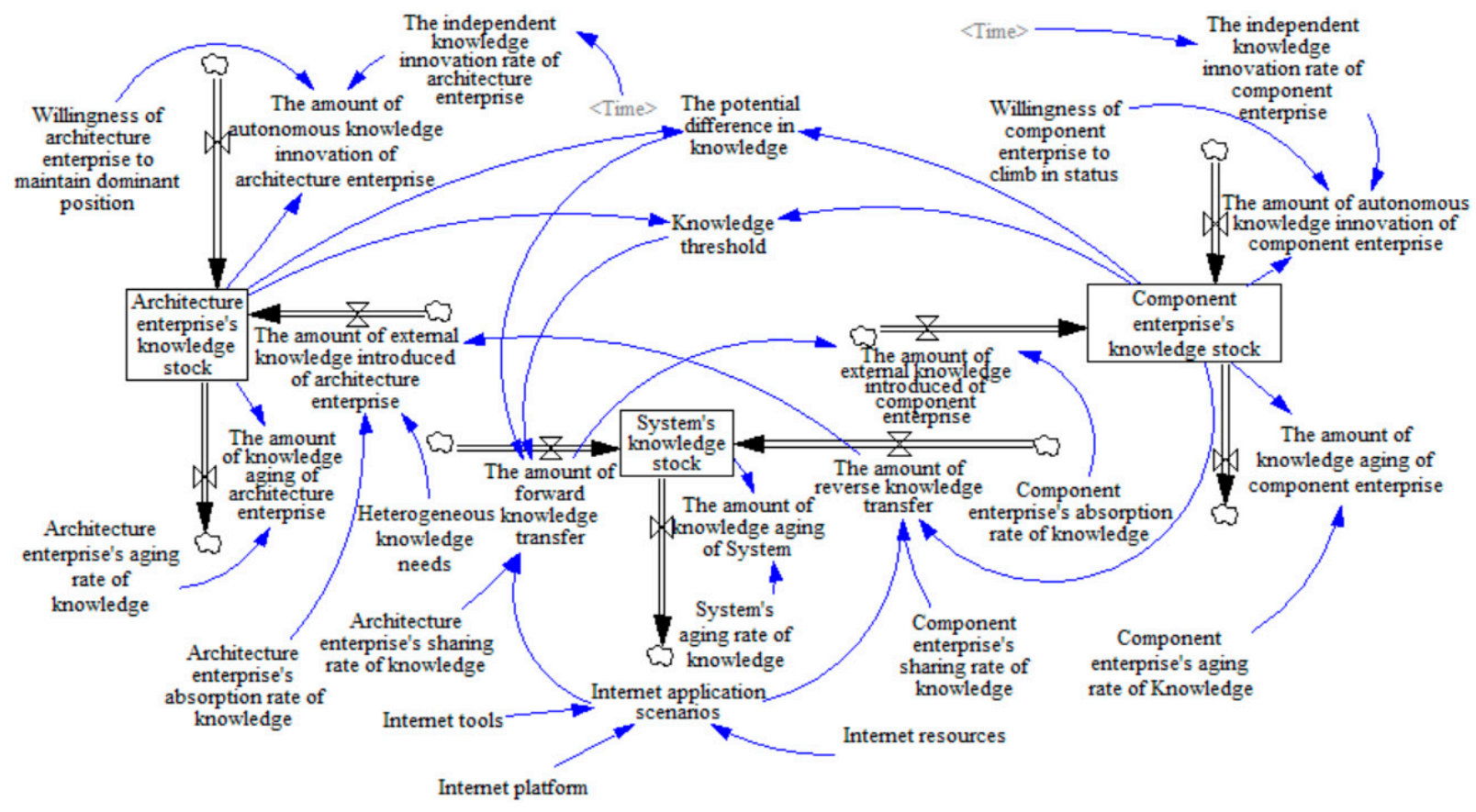

Figure 3. System flow chart. 
Table 2. Types of variables.

\begin{tabular}{|c|c|c|}
\hline Variable & Amount & Name \\
\hline State Variables (L) & 3 & $\begin{array}{l}\text { Architecture enterprise's knowledge stock (L1), Component enterprise's knowledge stock (L2), } \\
\text { System's knowledge stock (L3) }\end{array}$ \\
\hline Flow rate variables $(\mathrm{R})$ & 9 & $\begin{array}{l}\text { The amount of autonomous knowledge innovation of architecture enterprise (R1), The amount of } \\
\text { external knowledge introduced of architecture enterprise(R2), The amount of knowledge aging } \\
\text { of architecture enterprise (R3), The amount of autonomous knowledge innovation of component } \\
\text { enterprise (R4), The amount of external knowledge introduced of component enterprise (R5), The } \\
\text { amount of knowledge aging of component enterprise (R6), The amount of forward knowledge } \\
\text { transfer (R7), The amount of reverse knowledge transfer (R8), The amount of knowledge aging } \\
\text { of System (R9) }\end{array}$ \\
\hline Auxiliary variables (A) & 6 & $\begin{array}{l}\text { The independent knowledge innovation rate of architecture enterprise (A1), The independent } \\
\text { knowledge innovation rate of component enterprise (A2), Heterogeneous knowledge needs (A3), } \\
\text { The potential difference in knowledge (A4), Knowledge threshold (A5), Internet } \\
\text { application scenarios (A6) }\end{array}$ \\
\hline Constants (C) & 12 & $\begin{array}{l}\text { Willingness of architecture enterprise to maintain dominant position (C1), Architecture } \\
\text { enterprise's aging rate of knowledge (C2), Architecture enterprise's sharing rate of knowledge } \\
\text { (C3), Architecture enterprise's absorption rate of knowledge (C4), Willingness of component } \\
\text { enterprise to climb in status (C5), Component enterprise's aging rate of Knowledge (C6), } \\
\text { Component enterprise's sharing rate of knowledge (C7), Component enterprise's absorption rate } \\
\text { of knowledge (C8), System's aging rate of knowledge (C9), Internet tools (C10), Internet platform } \\
\text { (C11), Internet resources (C12) }\end{array}$ \\
\hline
\end{tabular}

\subsection{Model Equation Design and Parameter Explanation}

The behavior of organizations is largely determined by the structure of the organization $[19,59]$, and, therefore, the behavioral patterns and characteristics of the academic model depend primarily on the model structure rather than on specific parameter values. When building a qualitative model of the system's dynamics, there are essentially no fixed laws to follow and the quality of the model built depends heavily on the researcher's experience [60]. When modeling system dynamics, the focus should be on the causal structure of the model, reflecting the true dynamic behavior of the system and avoiding the one-sided pursuit of unnecessarily complex models [61].

Based on the existing research and the causal analysis in the previous paper, and considering the characteristics and actual situation of architecture enterprises and component enterprises in modular production, this paper designs and illustrates the equations from three aspects: Architecture enterprises, component enterprises, and innovation systems, as shown in Table 3.

Table 3. Model equation design and parameter explanation.

The initial value of the knowledge stock of the architecture enterprise is set to 100; in general, the knowledge stock of the component enterprise is

$\mathrm{L} 1=\mathrm{INTEG}(\mathrm{R} 1+\mathrm{R} 2-\mathrm{R} 3,80)$ L2 = INTEG $(\mathrm{R} 4+\mathrm{R} 5-\mathrm{R} 6,20)$; L3 = INTEG (R7 + R8 - R9, 0); smaller than that of the architecture enterprise, so the initial value of the knowledge stock of the component enterprise is set to 20; if no knowledge transfer occurs between the component enterprise and the architecture enterprise and there will be no knowledge stock in the innovation system, so the initial value of knowledge stock, in this case, is set to 0 .

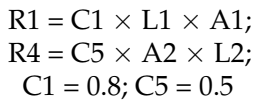

In addition to being closely related to the rate of knowledge innovation and the stock of knowledge, the amount of autonomous knowledge innovation by enterprises is also related to the subjective willingness to innovate.

The subjective reason for the introduction of external knowledge is the architecture enterprise's need for heterogeneous knowledge such as component-specific knowledge from the component enterprise, but the architecture enterprise will initiate the transfer of relevant knowledge to the component enterprise for reasons such as knowledge potential differences between the two sides.

Architecture enterprises, component enterprises, and innovation systems
made up of both face the problem of aging knowledge, which is
represented in this paper using a step function, with knowledge starting
to age at month 4.


Table 3. Cont.

\section{Design Equation}

A1 = WITH LOOKUP $($ Time,$([(0,0)-(30,1)],(0,0.1),(30,0.3)))$;

A2 = WITH LOOKUP (Time, $([(0,0)-(30,1)],(0,0.05),(30,0.25)))$

\section{Descriptions}

The process of change in the autonomous knowledge innovation rate of the architecture enterprises is represented using a table function, treated as a linear function of initially 0.1 and ultimately 0.3 ; the process of change in the autonomous knowledge innovation rate of component enterprises is also represented using a table function which is treated as a linear function of initially 0.05 and ultimately 0.25 .

The amount of forward knowledge transfer is calculated using a delay function, with 0.9 being the upper limit for the forward knowledge transfer and forward knowledge transfer stopping when the knowledge threshold is exceeded, with an initial transfer of 0 and a delay of 2-time units.

The knowledge threshold is calculated using a selection function, with the upper limit set at 0.9 .

The amount of reverse knowledge transfer is expressed using a delay function with an initial transfer of 0 and a delay of 2-time units.

Knowledge potential is the main driver of forward inter-enterprise knowledge transfer

Internet tools, Internet platforms, and Internet resources are forwardly correlated with the Internet scenario and take the value of a random variable between $[0,1]$.

\section{Simulation and Sensitivity Analyses}

\subsection{System Boundary Determination}

Forrester [59] argues that the delineation of the system boundaries must include all the structures that allow researchers to identify and develop an understanding of the causes of all relevant dynamic behaviors. However, the situation is so complex that no model can model reality in all of its details; it is a simplification of reality, and therefore requires boundary closure of the model according to the needs of the research. Systematic boundary tests examine whether the various covariates that are important to the problem under study are included in the model, whether there are important variables that are not considered in the model, and whether the model needs to be extended to include more content. The model should have appropriate boundaries; too small a boundary will not cover the important variables involved in the research problem, and too large a boundary will make the model less general. Reasonably fixed boundaries are critical to the success of the model.

The object of this paper is a knowledge transfer system consisting of architecture and component enterprises in a modular production to analyze the changing characteristics of knowledge transfer between architecture and component enterprises in different Internet contexts. Time issues and important variables closely related to the research topic are considered in the causality determination and model construction, while non-important endogenous variables and exogenous variables with less influence are excluded. Based on the existing studies and the causality analysis in the previous papers, the concepts and corresponding variables are developed and, finally, the model is revised and refined according to the actual situation.

\subsection{Simulation Analyses}

This paper uses Vensim PLE software to simulate, analyze, and construct a system dynamics model to examine whether the behavior and trends of the model can match the actual trends in the knowledge transfer between architecture and component enterprises in a modular production. According to Yang et al. [28], the Internet has evolved from its early beginnings as a class of technological systems to improve the efficiency of information dissemination (Internet tools) to an application platform for providing various online services (Internet platform), until it finally evolved into a class of man-made resources with different characteristics from natural resources (Internet resources). 
Therefore, in this paper, the initial value of Internet tools is set to 0.3 , the initial value of Internet platforms is set to 0.2 , and the initial value of Internet resources is set to 0.1 . The simulation time is set to 30 months, and the model simulation results are shown in Figure 4.

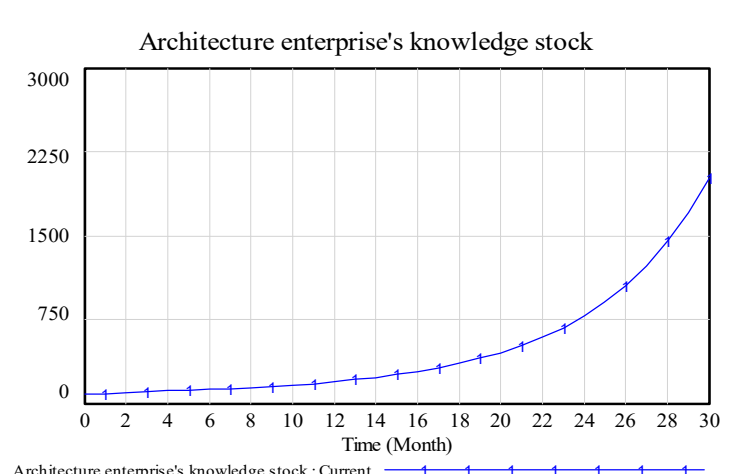

The amount of autonomous knowledge innovation of architecture enterprise
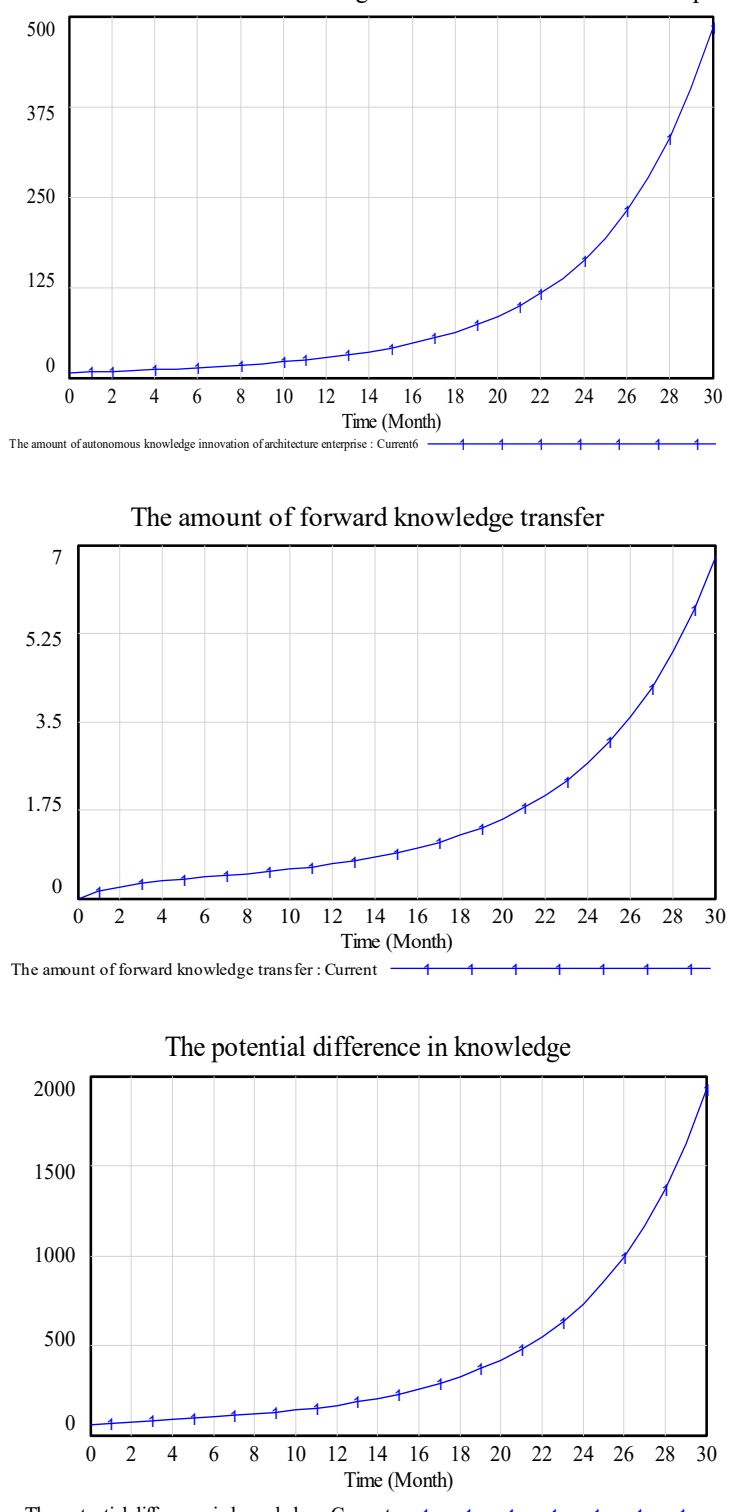

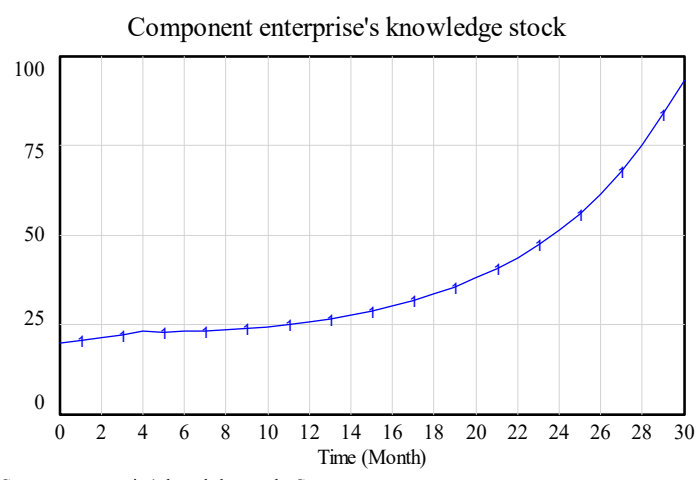

Component enterprise's knowledge stock : Current

The amount of autonomous knowledge innovation of component enterprise
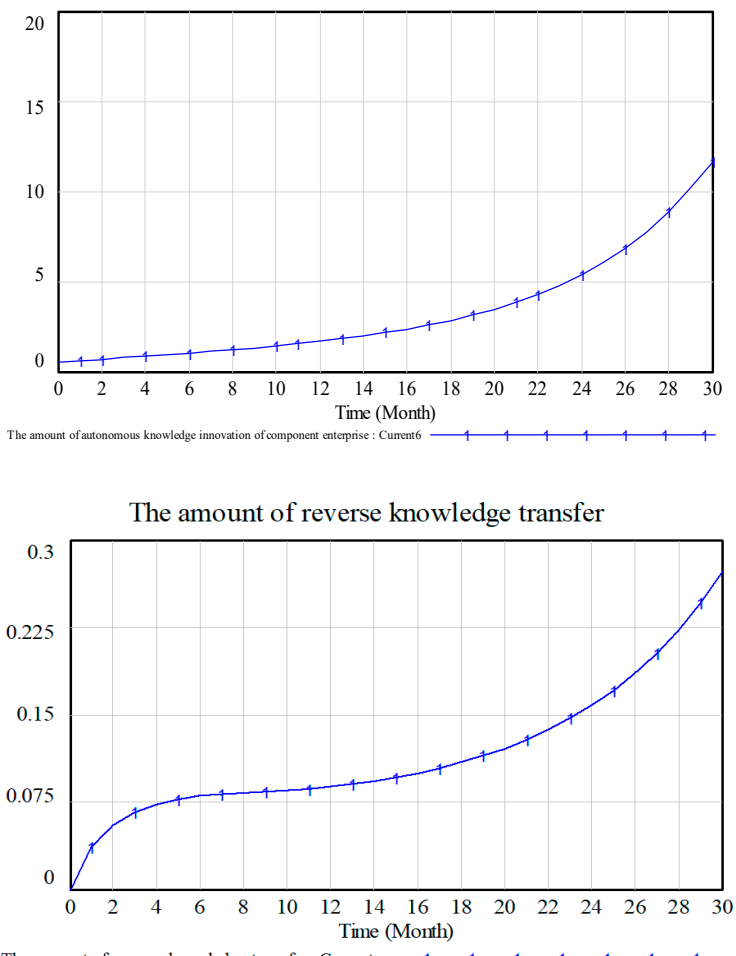

The amount of reverse knowledge tran sfer : Current

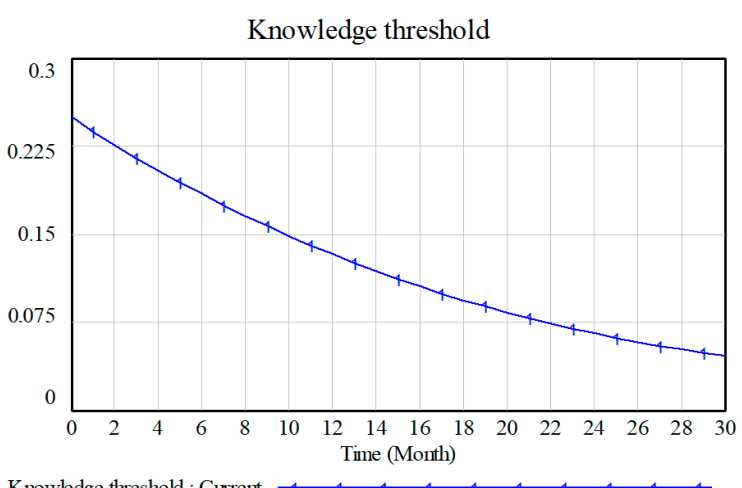

Figure 4. Simulation results. 
From the simulation results, it can be seen that the knowledge stock of both architecture enterprises and component enterprises tends to increase gradually over time; however, as the initial knowledge stock (difference of 60), independent knowledge innovation rate (difference of 0.05), and willingness to maintain the main status (difference of 0.3) of architecture enterprises are higher than that of component enterprises, there is a huge difference in the knowledge stock of both sides (difference of 1910) in the 30th month. Both architecture enterprises' autonomous knowledge innovation and component enterprises' autonomous knowledge innovation showed a gradual increase; however, because both the knowledge stock and the initial innovation rate were higher, this led to a greater increase in innovation in architecture enterprises. Both the amount of forward knowledge transfer and the amount of reverse knowledge transfer between the architecture enterprises and the component enterprises showed a trend of increasing transfer by first accelerating and then decelerating, therefore the inflection point of the change in the speed of knowledge transfer of architecture enterprises appears earlier than that of component enterprises. As the knowledge stock of architecture enterprises increases faster than that of component enterprises, the knowledge potential difference between the two gradually becomes larger and the knowledge threshold gradually becomes smaller.

In summary, the system dynamics model constructed in this paper based on the modular production network can better simulate the knowledge transfer between architecture enterprises and component enterprises in modular production in the Internet scenario, and the simulation results are more consistent with the time situation, indicating that the model is reasonable and effective.

\subsection{Extreme Conditions Test}

The extreme case test is designed to test whether each equation is stable and reliable when the variables take extreme values and whether it will appear to violate the laws of change of the real system. This is generally judged by the change in the model when one or more of the variables consider extreme values. Due to the space limitations, this paper selects Internet tools and Internet platforms to examine the impact of these two variables on the amount of knowledge transfer between architecture and component enterprises when each takes an extreme value of ' 1 ' The results are shown in Figure 5. It can be seen that, when the Internet tool and Internet platform are adjusted to 1 respectively, the trends of the forward and reverse knowledge transfer between the architecture and component enterprises are similar to those in Figure 4 at non-extreme values, except that the values show different variations. This indicates that the equations of the model are stable and reliable.

\subsection{Sensitivity Analysis}

Sensitivity analysis is used to analyze the sensitivity of a system to numerical adjustments by varying the parameters in the model to observe the degree of change in the curve. In this paper, a system dynamics model is constructed to examine the impact of the variables of Internet tools, Internet platforms, and Internet resources on the knowledge transfer process between architecture enterprises and component enterprises by gradually adjusting their values.

The other variables are kept constant and the Internet tools are increased from 0.3 to $0.4,0.5,0.6,0.7$, and 0.8 , respectively, with each curve noted as current1, current2, current3, current4, current5, and current6; the amount of knowledge transferred is shown in Figure 6 . It can be seen that, as time goes by after the Internet tool scenario is gradually improved, the knowledge transfer volume between the architecture enterprises and the component enterprises all show a gradual upward trend, and the curve of forward knowledge transfer volume gradually becomes steeper. In terms of the speed of transfer, the amount of forward knowledge transfer experienced a short stabilization period after a rapid increase in period 2 and began to increase more and more rapidly from period 14 onwards, while the amount of reverse knowledge transfer in the same period stabilized after a rapid increase 
in period 2 and began to increase more significantly after period 24 . Therefore, the gradual improvement of the Internet tool scenario is conducive to improving the ease of knowledge transfer between architecture and component enterprises, which can significantly increase the amount of knowledge transfer, and the rate of increase of forward knowledge transfer is higher than the rate of increase of reverse knowledge transfer.
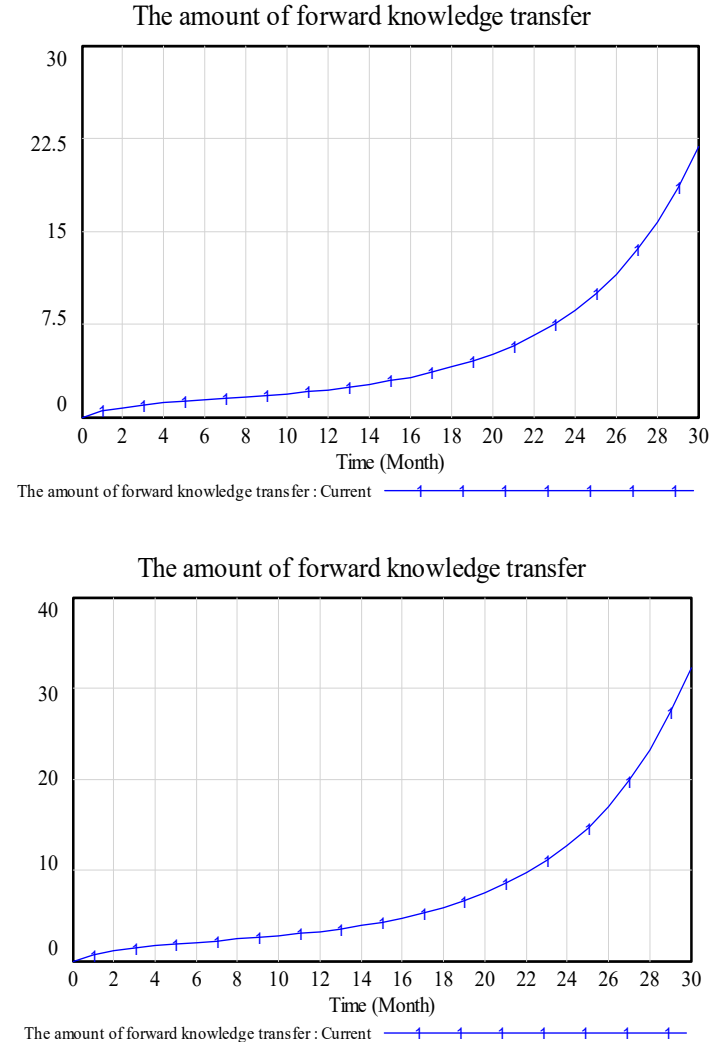
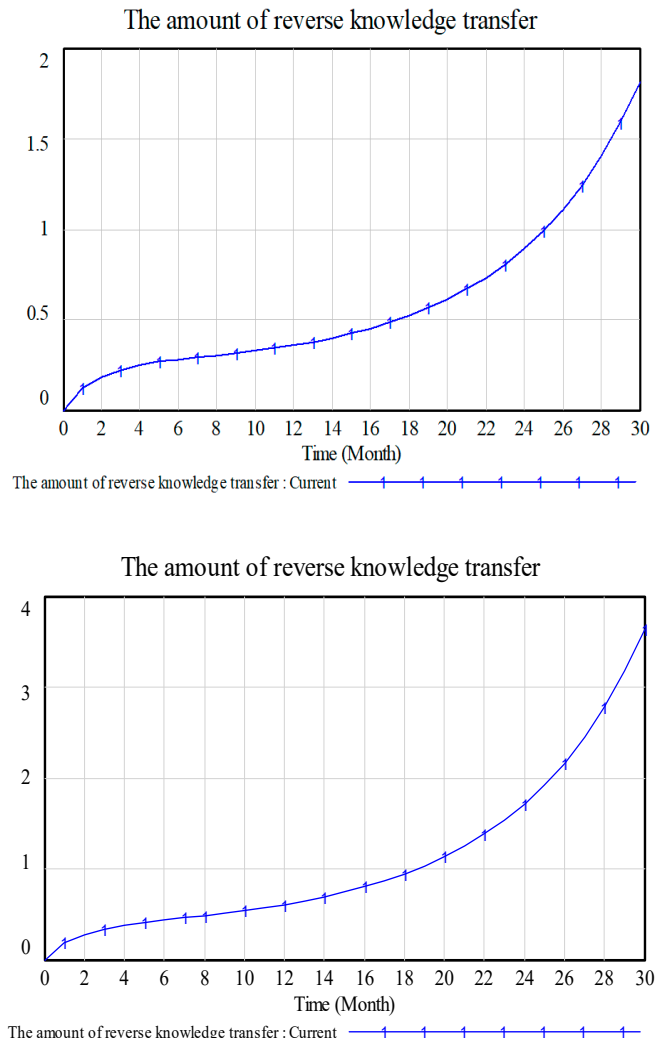

Figure 5. Extreme conditions test results.
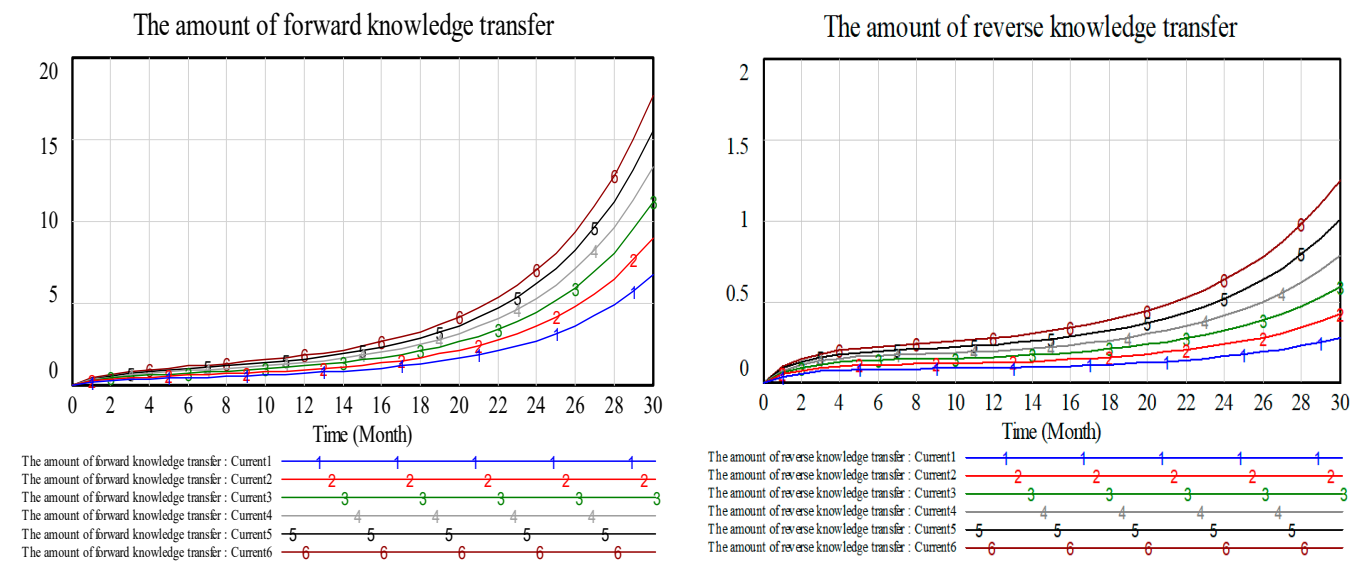

Figure 6. Adjusting the results of sensitivity analysis of Internet tools.

Other variables were kept constant and the Internet platform was increased from 0.2 to $0.3,0.4,0.5,0.6$, and 0.7 , respectively, with each curve noted as current 1 , current 2 , current3, current4, current5, and current6. The knowledge transfer volumes are shown in Figure 7. When gradually adjusting to the Internet platform scenario, both the amount of forward and reverse knowledge transfer showed a more significant upward trend over time than the Internet tool scenario. Further, the reverse knowledge transfer curve gradually became steeper, i.e., the reverse knowledge transfer increased at a faster rate. The Internet platform 
scenario is more conducive to knowledge transfer between architecture enterprises and component enterprises than the Internet tool scenario, and the reverse knowledge transfer increased faster than the forward knowledge transfer.
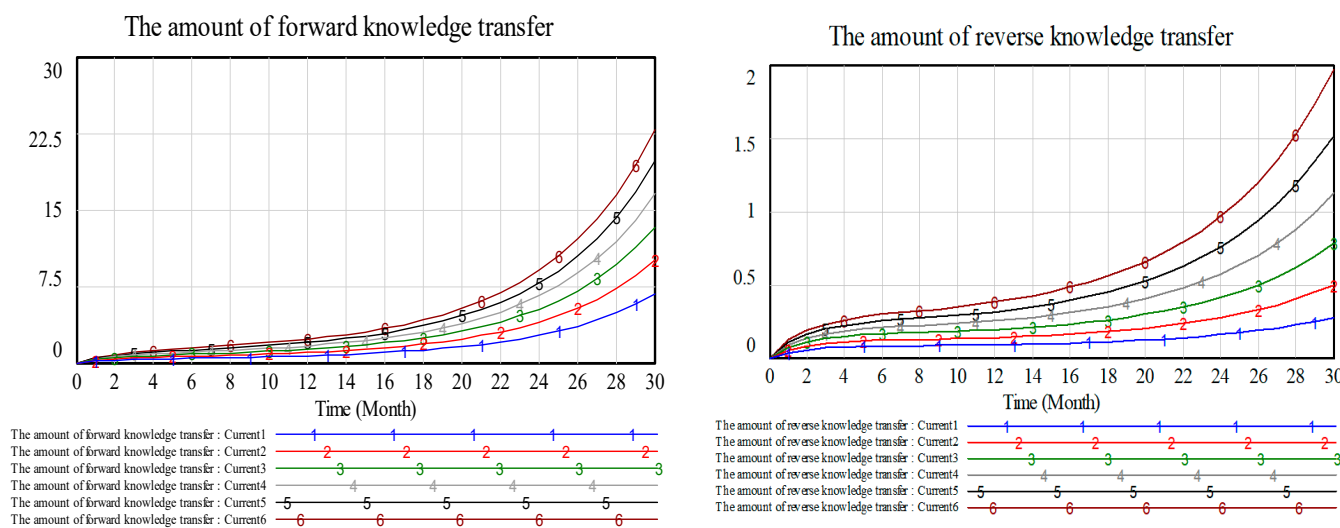

Figure 7. Adjusting the results of sensitivity analysis for Internet platforms.

The other variables were kept constant and the Internet resources were increased from 0.1 to $0.2,0.3,0.4,0.5$, and 0.6 , respectively, with each curve noted as current1, current2, current3, current4, current5, and current6; the amount of knowledge transfer is shown in Figure 8. As can be seen, the trend of the curves of the two variables examined showed an upward trend when the Internet resource scenario was gradually increased. Moreover, the larger the Internet resource scenario, the steeper the curve of the reverse knowledge transfer volume and the faster the variable increases. Internet resources have richer connotations and extensions than Internet tools and Internet platforms, and the greater the consumption of Internet resources, the greater the total amount of resources becomes instead [29], which has a more profound impact on the knowledge transfer system constituted by architecture and component enterprises in modular production, with easier methods of inter-enterprise interaction. In terms of the amount of knowledge transferred, the impact of Internet resources on inter-enterprise knowledge transfer is higher than the impact of Internet tools and Internet platforms. Therefore, the Internet resource scenario can more significantly facilitate knowledge transfer between architecture and component enterprises, and the amount of forward knowledge transfer increases more rapidly than the amount of reverse knowledge transfer.
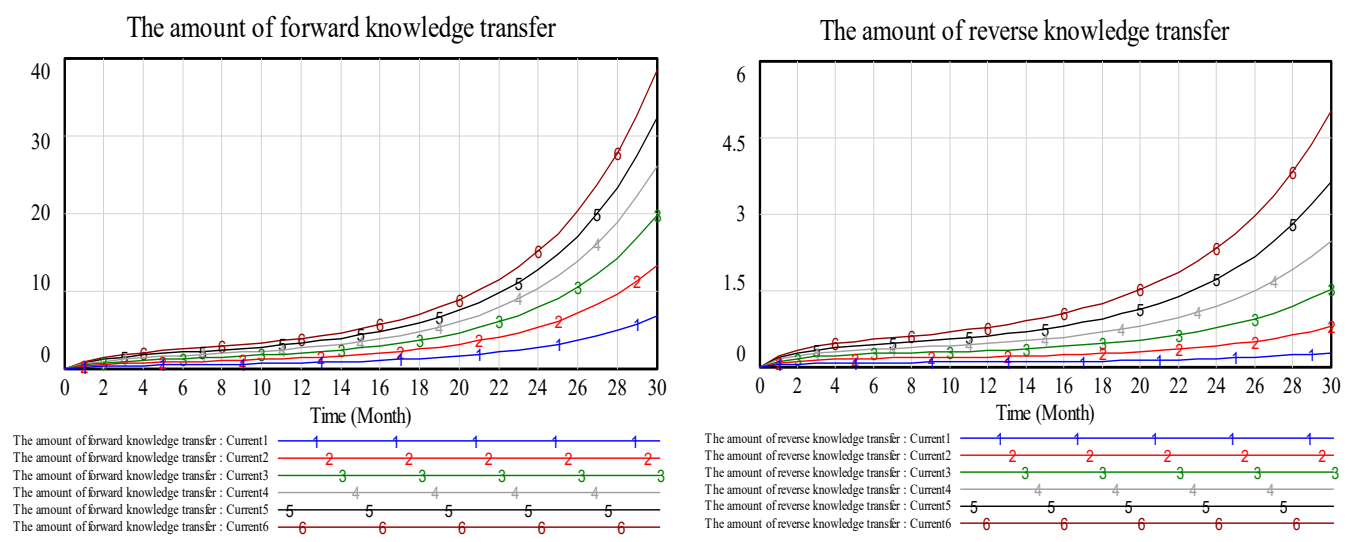

Figure 8. Adjusting the results of sensitivity analysis of Internet resources.

\section{Conclusions and Implications}

This paper constructs a system dynamics model with architecture enterprises and component enterprises in a modular production network as the research object, and uses Vensim PLE software to test the model and conduct sensitivity analysis, drawing the following conclusions. (1) All three Internet scenarios, namely Internet tools, Internet 
platforms, and Internet resources, can facilitate forward and reverse knowledge transfer between architecture enterprises and component enterprises and show a trend of gradually increasing facilitation. (2) Internet tools and Internet resources are more conducive to forward knowledge transfer from architecture enterprises to component enterprises, while Internet platforms have a stronger facilitating effect on reverse knowledge transfer from component enterprises to architecture enterprises.

Previous studies have only demonstrated that Internet applications enhance interenterprise knowledge dissemination and analysis [7-9], breaking through the spatial and temporal limitations of knowledge transfer [10]. This paper subdivides Internet applications into three contexts: Internet tools, Internet platforms, and Internet resources, and investigates the differential impact of different Internet application contexts on interenterprise knowledge transfer. Most previous studies are based on qualitative and empirical research, ignoring the interaction of cause and effect as well as the cumulative effect over time. This study uses a system dynamics approach to investigate knowledge transfer between architecture enterprises and component enterprises, considering the dynamic evolution process of each influencing element of inter-enterprise knowledge transfer.

\subsection{Theoretical Contributions}

The research findings in this paper also provide some theoretical contributions. (1) Our research focuses on the role of different Internet scenarios in knowledge transfer. Under the integrated perspective of knowledge management theory and complex systems theory, we comprehensively and systematically analyze the role of three scenarios-Internet tools, Internet platforms, and Internet resources-in knowledge transfer, and our findings show that the three scenarios-Internet tools, Internet platforms, and Internet resources-show a trend of gradually increasing facilitation of knowledge transfer. This indicates that, although the three Internet scenarios exist simultaneously in reality, their impacts on knowledge transfer are different. In particular, the Internet resource scenario plays an increasingly significant role in the economic system, where the expression of information changes from atoms to 'bits', and it greatly facilitates inter-enterprise knowledge transfer. Our findings, therefore, contribute to the study of scenario factors of knowledge transfer. (2) Our study also demonstrates the differential impact of different Internet scenarios on the knowledge transfer between architecture enterprises and component enterprises, which helps enterprises to make full use of different Internet scenarios to facilitate knowledge transfer and thus increase their knowledge accumulation. Thus, this study enriches and extends the theory of knowledge management.

\subsection{Managerial Implications}

This paper provides the following insights for management to improve knowledge transfer performance between architecture and component enterprises from the perspective of different Internet scenarios. In the process of processing, producing, and designing the modules (components) of architecture enterprises, component enterprises should focus on shaping favorable knowledge transfer scenarios, accelerating their digital transformation, and improving their ability to integrate, digest, absorb, and recreate forward knowledge transfer. Component enterprises must focus on improving their innovation capabilities and reducing the gap between their innovation capabilities and those of the architecture. Under the premise of ensuring the compatibility of "contracted" modules, i.e., following common interface standards, and with the addition of big data resources from the Internet, component enterprises can quickly accumulate customer and market-related knowledge, improve the design of the "contracted" modules, enhance their functionality, and reduce manufacturing lead times. Through the incremental innovation of modules, component enterprises can increase the amount of independent knowledge innovation and ultimately increase the accumulation of knowledge stock. 


\subsection{Limitations and Future Research Directions}

Limitations of this paper and suggestions for future research are as follows. First, inter-enterprise knowledge transfer in the modular production process of manufacturing enterprises is a very complex and abstract process, and only some key factors are considered in this paper. Some variables in the model are simplified, and knowledge transfer is also simplified to take place in both directions between architecture enterprises and component enterprises; therefore, the construction of a complex dynamic model construction containing more key factors and multiple enterprise subjects requires further research. Secondly, this paper mainly studies knowledge transfer from the contextual factors of enterprise transfer, ignoring factors such as employee innovation ability, which is closely related to tacit knowledge transfer [62], and future research can consider the influence of subject factors and contextual factors of knowledge transfer on knowledge transfer comprehensively. Finally, this paper adopts a system dynamics approach to carry out the research and draws corresponding results, and future studies should focus on further validating the conclusions of this paper by selecting specific cases and collecting objective data.

Author Contributions: Conceptualization, methodology, validation, formal analysis, investigation, resources, data curation, writing - original draft preparation, writing-review, and editing, are all handled by X.L. (Xingong Li) and X.L. (Xiaokai Li). All authors have read and agreed to the published version of the manuscript.

Funding: This research was funded by the National Social Science Foundation of China (Grant No.20BJY037), the Graduate Education Innovation and Quality Improvement Project of Henan University (Grant No. SYL20060161).

Institutional Review Board Statement: Not applicable.

Informed Consent Statement: Not applicable.

Data Availability Statement: No new data were created or analyzed in this study. Data sharing does not apply to this article.

Acknowledgments: The article was supported by the National Social Science Foundation of China, the Graduate Education Innovation and Quality Improvement Project of Henan University.

Conflicts of Interest: The authors declare no conflict of interest.

\section{References}

1. Teece, D.J. Technology Transfer by Multinational Firms: The Resource Cost of Transferring Technological Know-How. Econ. J. 1977, 87, 242-261. [CrossRef]

2. Yap, X.S.; Rasiah, R. Catching up and leapfrogging in a high-tech manufacturing industry: Towards a firm-level taxonomy of knowledge accumulation. Knowl. Manag. Res. Pract. 2015, 15, 114-129. [CrossRef]

3. DeCarolis, D.M.; Deeds, D.L. The impact of stocks and flows of organizational knowledge on firm performance: An empirical investigation of the biotechnology industry. Strateg. Manag. J. 1999, 20, 953-968. [CrossRef]

4. Lavie, D. The competitive advantage of interconnected firms: An extension of the resource-based view. Acad. Manag.Rev. 2006, 31, 638-658. [CrossRef]

5. Barão, A.; de Vasconcelos, J.B.; Rocha, Á.; Pereira, R. A knowledge management approach to capture organizational learning networks. Int. J. Inf. Manag. 2017, 37, 735-740. [CrossRef]

6. West, J.; Salter, A.; Vanhaverbeke, W.; Chesbrough, H. Open innovation: The next decade. Res. Policy 2014, 43, 805-811. [CrossRef]

7. Chesbrough, H.; Bogers, M. Explicating open innovation: Clarifying an emerging paradigm for understanding innovation. In New Frontiers in Open Innovation; Chesbrough; Vanhaverbeke, W., West, J., Eds.; Oxford University Press: Oxford, UK, 2014 ; pp. 3-28.

8. Alavi, M.; Leidner, D.E. Knowledge management and knowledge management systems: Conceptual foundations and research issues. MIS Q. 2001, 25, 107-136. [CrossRef]

9. Forman, C.; van Zeebroeck, N. Digital technology adoption and knowledge flows within firms: Can the Internet overcome geographic and technological distance? Res. Policy 2019, 48, 103697. [CrossRef]

10. Bloom, N.; Garicano, L.; Sadun, R.; Van Reenen, J. The distinct effects of information technology and communication technology on firm organization. Manag. Sci. 2014, 60, 2859-2885. [CrossRef]

11. OECD. OECD Digital Economy Outlook 2020; OECD Publishing: Paris, France, 2020. [CrossRef]

12. Fine, C.; Whitney, D. Is the Make-Buy Decision Process a Core Competence? In Logistics in the Information Age—Proceedings of 4th International Symposium on Logistics; Muffatto, M., Pawar, K., Eds.; Servizi Grafici Editoriali: Padova, Italy, 1999 ; pp. $31-63$. 
13. Takeishi, A. Knowledge Partitioning in the Interfirm Division of Labor: The Case of Automotive Product Development. Organ. Sci. 2002, 13, 321-338. [CrossRef]

14. Lee, J.; Veloso, F.M. Interfirm innovation under uncertainty: Empirical evidence for strategic knowledge partitioning. J. Prod. Innov. Manag. 2008, 25, 418-435. [CrossRef]

15. Henderson, R.M.; Clark, K.B. Architectural Innovation: The Reconfiguration of Existing Product Technologies and the Failure of Established Firms. Adm. Sci. Q. 1990, 35, 9. [CrossRef]

16. Lakemond, N.; Berggren, C.; Weele, A. Coordinating supplier involvement in product development projects: A differentiated coordination typology. RED Manag. 2006, 36, 55-66. [CrossRef]

17. Brusoni, S.; Prencipe, A.; Pavitt, K. Knowledge specialization, organizational coupling, and the boundaries of the firm: Why do firms know more than they make? Adm. Sci. Q. 2001, 46, 597-621. [CrossRef]

18. Prencipe, A. Technological competencies and product's evolutionary dynamics a case study from the aero-engine industry. Res. Policy 1997, 25, 1261-1276. [CrossRef]

19. Wang, J.; Zhang, R.; Hao, J.-X.; Chen, X. Motivation factors of knowledge collaboration in virtual communities of practice: A perspective from system dynamics. J. Knowl. Manag. 2019, 23, 466-488. [CrossRef]

20. Clark, K.B. The interaction of design hierarchies and market concepts in technological evolution. Res. Policy 1985, 14, 235-251. [CrossRef]

21. Sanchez, R.; Mahoney, J.T. Modularity, flexibility, and knowledge management in product and organization design. Strat. Manag. J. 1996, 17, 63-76. [CrossRef]

22. Baldwin, C.Y.; Clark, K.B.; Clark, K.B. Design Rules: The Power of Modularity; MIT Press: Cambridge, MA, USA, $2000 ;$ Volume 1.

23. Yoo, Y.; Henfridsson, O.; Lyytinen, K. Research commentary-The new organizing logic of digital innovation: An agenda for information systems research. Inf. Syst. Res. 2010, 21, 724-735. [CrossRef]

24. MacDuffe, J.P.; Helper, S. Collaboration in Supply Chains: With and Without Trust. In Collaborative Community; Heckscher, C., Adler, P.S., Eds.; Oxford University Press: New York, NY, USA, 2005.

25. Crespo, C.F.; Griffith, D.A.; Lages, L.F. The performance effects of vertical and horizontal subsidiary knowledge outflows in multinational corporations. Int. Bus. Rev. 2014, 23, 993-1007. [CrossRef]

26. Szulanski, G. Exploring internal stickiness: Impediments to the transfer of best practice within the firm. Strat. Manag. J. 1996, 17, 27-43. [CrossRef]

27. Holtshouse, D. Knowledge research issues. Calif. Manag. Rev. 1998, 40, 277-280. [CrossRef]

28. Yang, S.; Zhou, K.; Zhang, Q.; Fan, W.; Ding, S.; Yu, B. A resource view of the Internet. J. Manag. Sci. China 2016, $19,1-11$.

29. Xuetong, Y. Bipolar Rivalry in the Early Digital Age. Chin. J. Int. Politics 2020, 13, 313-341. [CrossRef]

30. Simonin, B.L. An empirical investigation of the process of knowledge transfer in international strategic alliances. J. Int. Bus. Stud. 2004, 35, 407-427. [CrossRef]

31. Zander, U.; Kogut, B. Knowledge and the Speed of the Transfer and Imitation of Organizational Capabilities: An Empirical Test. Organ. Sci. 1995, 6, 76-92. [CrossRef]

32. Polanyi, M. Personal Knowledge: Towards a Post-Critical Philosophy; University of Chicago Press: Chicago, IL, USA, 1962.

33. Cummings, J.L.; Teng, B.-S. Transferring R\&D knowledge: The key factors affecting knowledge transfer success. J. Eng. Technol. Manag. 2003, 20,39-68. [CrossRef]

34. Nonaka, I.; Konno, N. The Concept of "Ba": Building a Foundation for Knowledge Creation. Calif. Manag. Rev. 1998, 40, 40-54. [CrossRef]

35. Søberg, P.V.; Chaudhuri, A. Technical knowledge creation: Enabling tacit knowledge use. Knowl. Process. Manag. 2018, 25, 88-96. [CrossRef]

36. Al-Salti, Z.; Hackney, R. Factors impacting knowledge transfer success in information systems outsourcing. J. Enterp. Inf. Manag. 2011, 24, 455-468. [CrossRef]

37. Liao, S.-H.; Hu, T.-C. Knowledge transfer and competitive advantage on environmental uncertainty: An empirical study of the Taiwan semiconductor industry. Technovation 2007, 27, 402-411. [CrossRef]

38. Nonaka, I.; Takeuchi, H. The Knowledge-Creating Company: How Japanese Enterprises Create the Dynamics of Innovation; Oxford University press: Oxford, UK, 1995.

39. Gertler, M.S. Tacit knowledge and the economic geography of context, or The undefinable tacitness of being (there). J. Econ. Geogr. 2003, 3, 75-99. [CrossRef]

40. Michalakis, K.; Aliprantis, J.; Caridakis, G. Visualizing the Internet of Things: Naturalizing Human-Computer Interaction by Incorporating AR Features. IEEE Consum. Electron. Mag. 2018, 7, 64-72. [CrossRef]

41. Chennamaneni, A.; Teng, J.T. An Integrated Framework for Effective Tacit Knowledge Transfer. AMCIS 2011 Proceedings All Submissions. Available online: https:/ / aisel.aisnet.org/amcis2011_submissions/277 (accessed on 24 June 2011).

42. Glavas, C.; Mathews, S. How international entrepreneurship characteristics influence Internet capabilities for the international business processes of the firm. Int. Bus. Rev. 2014, 23, 228-245. [CrossRef]

43. Mathews, S.; Bianchi, C.; Perks, K.; Healy, M.; Wickramasekera, R. Internet marketing capabilities and international market growth. Int. Bus. Rev. 2016, 25, 820-830. [CrossRef]

44. Wang, V.X.; Hitch, L. Is Active Learning via Internet Technologies Possible? Int. J. Online Pedagog. Course Des. 2017, 7, 48-59. [CrossRef] 
45. Glavas, C.; Mathews, S.; Bianchi, C. International opportunity recognition as a critical component for leveraging Internet capabilities and international market performance. J. Int. Entrep. 2016, 15, 1-35. [CrossRef]

46. Sigfusson, T.; Chetty, S. Building international entrepreneurial virtual networks in cyberspace. J. World Bus. 2013, 48, 260-270. [CrossRef]

47. Maiti, M.; Vuković, D.; Mukherjee, A.; Paikarao, P.D.; Yadav, J.K. Advanced data integration in banking, financial, and insurance software in the age of COVID-19. Softw. Pract. Exp. 2021, 1-17. [CrossRef]

48. Watson, J.H.; Marjanovic, O. Big data: The fourth data management generation. Bus. Intell. J. 2013, 18, 4-8.

49. Goswami, P.; Mukherjee, A.; Maiti, M.; Tyagi, S.K.S.; Yang, L. A Neural Network Based Optimal Resource Allocation Method for Secure IIoT Network. IEEE Internet Things J. 2021, 1. [CrossRef]

50. Zhuang, Y.; Song, J.; Wu, F.; Li, X.; Zhang, Z.; Rui, Y. Multimodal Deep Embedding via Hierarchical Grounded Compositional Semantics. IEEE Trans. Circuits Syst. Video Technol. 2016, 28, 76-89. [CrossRef]

51. Langlois, R.N. Modularity in technology and organization. J. Econ. Behav. Organ. 2002, 49, 19-37. [CrossRef]

52. Maiti, M.; Krakovich, V.; Shams, S.R.; Vukovic, D.B. Resource-based model for small innovative enterprises. Manag. Decis. 2020, 58, 1525-1541. [CrossRef]

53. Galati, F.; Bigliardi, B. Redesigning the model of the initiation and evolution of inter-firm knowledge transfer in R\&D relationships. J. Knowl. Manag. 2019, 23, 2039-2066. [CrossRef]

54. Zhang, H.; Zhou, M.; Rao, H.; Zhou, D. Dynamic simulation research on the effect of resource heterogeneity on knowledge transfer in R\&D alliances. Knowl. Manag. Res. Pract. 2021, 19, 370-386. [CrossRef]

55. Chen, H.; Jiang, N.; Fan, J. The Modeling and Analysis of System Dynamics about the Effect of Transfer Context on the Knowledge Transfer from Parent Company to Subsidiary. Manag. Rev. 2017, 62-71. [CrossRef]

56. Wang, W.-T. System dynamics modelling for examining knowledge transfer during crises. Syst. Res. Behav. Sci. 2011, 28, 105-127. [CrossRef]

57. Garud; Kumaraswamy Vicious and Virtuous Circles in the Management of Knowledge: The Case of Infosys Technologies. MIS Q. 2005, 29, 9. [CrossRef]

58. Paucar-Caceres, A.; Pagano, R. Systems thinking and the use of systemic methodologies in knowledge management. Syst. Res. Behav. Sci. 2009, 26, 343-355. [CrossRef]

59. Forrester, J.W. System dynamics, systems thinking, and soft OR. Syst. Dyn. Rev. 1994, 10, 245-256. [CrossRef]

60. Forrester, J.W. Lessons from system dynamics modeling. Syst. Dyn. Rev. 1987, 3, 136-149. [CrossRef]

61. Repenning, N.P. Selling system dynamics to (other) social scientists. Syst. Dyn. Rev. 2003, 19, 303-327. [CrossRef]

62. Li, X.; Xue, J.; Liu, J. Linking leader humility to employee creative performance: Work engagement as a mediator. Soc. Behav. Pers. Int. J. 2021, 49, 1-7. [CrossRef] 